\title{
Association of extent of cannabis use and psychotic like intoxication experiences in a multi-national sample of first episode psychosis patients and controls
}

Citation for published version (APA):

Sami, M., Quattrone, D., Ferraro, L., Tripoli, G., La Cascia, E., Gayer-Anderson, C., Selten, J. P., Arango, C., Bernardo, M., Tarricone, I., Tortelli, A., Gatto, G., del Peschio, S., Del-Ben, C. M., Rutten, B. P., Jones, P. B., van Os, J., de Haan, L., Morgan, C., ... Di Forti, M. (2021). Association of extent of cannabis use and psychotic like intoxication experiences in a multi-national sample of first episode psychosis patients and controls. Psychological Medicine, 51(12), 2074-2082. [0033291720000847].

https://doi.org/10.1017/S0033291720000847

Document status and date:

Published: 01/09/2021

DOI:

$10.1017 / \mathrm{S} 0033291720000847$

Document Version:

Publisher's PDF, also known as Version of record

Document license:

Taverne

Please check the document version of this publication:

- A submitted manuscript is the version of the article upon submission and before peer-review. There can be important differences between the submitted version and the official published version of record. People interested in the research are advised to contact the author for the final version of the publication, or visit the DOI to the publisher's website.

- The final author version and the galley proof are versions of the publication after peer review.

- The final published version features the final layout of the paper including the volume, issue and page numbers.

Link to publication

\footnotetext{
General rights rights.

- You may freely distribute the URL identifying the publication in the public portal. please follow below link for the End User Agreement:

www.umlib.nl/taverne-license

Take down policy

If you believe that this document breaches copyright please contact us at:

repository@maastrichtuniversity.nl

providing details and we will investigate your claim.
}

Copyright and moral rights for the publications made accessible in the public portal are retained by the authors and/or other copyright owners and it is a condition of accessing publications that users recognise and abide by the legal requirements associated with these

- Users may download and print one copy of any publication from the public portal for the purpose of private study or research.

- You may not further distribute the material or use it for any profit-making activity or commercial gain

If the publication is distributed under the terms of Article 25fa of the Dutch Copyright Act, indicated by the "Taverne" license above, 
Psychological Medicine

cambridge.org/psm

\section{Original Article}

*Collaborators: Ulrich Reininghaus, Kathryn Hubbard, Stephanie Beards, Simona A. Stilo, Antonio Lasalvia, Caitlin Turner, Pierre-Michel Llorca, Julio Bobes, Miguel Bernardo, Julio Sanjuán, Jose Luis Santos, Manuel Arrojo, Mara Parellada, Pedro Cuadrado, José Juan Rodríguez Solano, Angel Carracedo, Enrique García Bernardo, Eva Velthorst, Laura Roldán, Gonzalo López, Bibiana Cabrera, Esther Lorente-Rovira, Paz Garcia-Portilla, Javier Costas, Estela Jiménez-López, Mario Matteis, Marta Rapado, Emiliano González, Covadonga Martínez, Emilio Sánchez, Ma Soledad Olmeda, Nathalie Franke, Fabian Termorshuizen, Daniella van Dam, Elsje van der Ven, Elles Messchaart, Marion Leboyer, Franck Schürhoff, Stéphane Jamain, Flora Frijda, Grégoire Baudin, Aziz Ferchiou, Baptiste Pignon, JeanRomain Richard, Thomas Charpeaud, AnneMarie Tronche, Giovanna Marrazzo, Lucia Sideli, Crocettarachele Sartorio, Fabio Seminerio, Camila Marcelino Loureiro, Rosana Shuhama, Mirella Ruggeri, Sarah Tosato, Chiara Bonetto, Doriana Cristofalo

Cite this article: Sami M et al (2021). Association of extent of cannabis use and psychotic like intoxication experiences in a multi-national sample of first episode psychosis patients and controls. Psychological Medicine 51, 2074-2082. https://doi.org/ $10.1017 /$ S0033291720000847

Received: 21 August 2019 Revised: 29 February 2020 Accepted: 19 March 2020

First published online: 28 April 2020

\section{Key words:}

Psychotic-like experiences; psychotomimetic; schizophrenia; substance abuse

Author for correspondence:

Musa Sami, E-mail: musa.sami@nottingham. ac.uk

(c) The Author(s), 2020. Published by Cambridge University Press

\section{CAMBRIDGE} UNIVERSITY PRESS

\section{Association of extent of cannabis use and psychotic like intoxication experiences in a multi-national sample of first episode psychosis patients and controls*}

\author{
Musa Sami ${ }^{1,2}$ (D), Diego Quattrone ${ }^{3}$, Laura Ferraro ${ }^{4}$, Giada Tripoli ${ }^{1}$, \\ Erika La Cascia ${ }^{4}$, Charlotte Gayer-Anderson ${ }^{5}$, Jean-Paul Selten ${ }^{6,7}$, Celso Arango ${ }^{8}$, \\ Miguel Bernardo ${ }^{9}$, Ilaria Tarricone ${ }^{10}$, Andrea Tortelli ${ }^{11}$, Giusy Gatto ${ }^{10}$, \\ Simona del Peschio ${ }^{10}$, Cristina Marta Del-Ben ${ }^{12}$, Bart P. Rutten ${ }^{7}$, \\ Peter B. Jones ${ }^{13,14}$, Jim van Os ${ }^{1,7,15}$, Lieuwe de Haan ${ }^{16}$, Craig Morgan ${ }^{5}$, \\ Cathryn Lewis ${ }^{3}$, Sagnik Bhattacharyya ${ }^{1}$, Tom P. Freeman ${ }^{17,18}$, Michael Lynskey ${ }^{18}$, \\ Robin M. Murray ${ }^{1}$ and Marta Di Forti ${ }^{3}$
}

\begin{abstract}
${ }^{1}$ Department of Psychosis Studies, Institute of Psychiatry, King's College London, De Crespigny Park, Denmark Hill, London, SE5 8AF, UK; ${ }^{2}$ Institute of Mental Health, Jubilee Campus, University of Nottingham, Nottingham, UK; ${ }^{3}$ Social, Genetic and Developmental Psychiatry Centre, Institute of Psychiatry, Psychology and Neuroscience, King's College London, London, SE5 8AF, UK; ${ }^{4}$ Department of Experimental Biomedicine and Clinical Neuroscience, University of Palermo, Via G. La Loggia 1, 90129 Palermo, Italy; ${ }^{5}$ Department of Health Service and Population Research, Institute of Psychiatry, King's College London, De Crespigny Park, Denmark Hill, London, SE5 8AF, UK; ${ }^{6}$ Rivierduinen Institute for Mental Health Care, Sandifortdreef 19, 2333 ZZ Leiden, The Netherlands; ${ }^{7}$ Department of Psychiatry and Neuropsychology, School for Mental Health and Neuroscience, South Limburg Mental Health Research and Teaching Network, Maastricht University Medical Centre, P.O. Box 616, 6200 MD Maastricht, The Netherlands; ${ }^{8}$ Department of Child and Adolescent Psychiatry, Hospital General Universitario Gregorio Marañón, School of Medicine, Universidad Complutense, liSGM (CIBERSAM), C/Doctor Esquerdo 46, 28007 Madrid, Spain; ${ }^{9}$ Department of Medicine, Barcelona Clinic Schizophrenia Unit, Neuroscience Institute, Hospital clinic, University of Barcelona, IDIBAPS, CIBERSAM, Barcelona, Spain; ${ }^{10}$ Department of Medical and Surgical Science, Psychiatry Unit, Alma Mater Studiorum Università di Bologna, Viale Pepoli 5, 40126 Bologna, Italy; ${ }^{11}$ Etablissement Public de Santé Maison Blanche, Paris, 75020, France; ${ }^{12}$ Division of Psychiatry, Department of Neuroscience and Behaviour, Ribeirão Preto Medical School, University of São Paulo, São Paulo, Brazil;

${ }^{13}$ Department of Psychiatry, University of Cambridge, Herchel Smith Building for Brain \& Mind Sciences, Forvie Site, Robinson Way, Cambridge, CB2 OSZ, UK; ${ }^{14}$ CAMEO Early Intervention Service, Cambridgeshire \& Peterborough NHS Foundation Trust, Cambridge, CB21 5EF, UK; ${ }^{15}$ Brain Centre Rudolf Magnus, Utrecht University Medical Centre, Utrecht, The Netherlands; ${ }^{16}$ Department of Psychiatry, Early Psychosis Section, Academic Medical Centre, University of Amsterdam, Meibergdreef 5, 1105 AZ Amsterdam, The Netherlands; ${ }^{17}$ Department of Psychology, Addiciton and Mental Health Group (AIM), University of Bath, BA2 7AY, UK and ${ }^{18}$ National Addiction Centre, Institute of Psychiatry, Psychology \& Neuroscience, King's College London, 4 Windsor Walk, London SE5 8BB, UK
\end{abstract}




\section{Introduction}

There is consistent evidence supporting an association between cannabis use and later psychosis (Myles, Myles, \& Large, 2015). Further, patterns of cannabis use in first episode psychosis (FEP) patients are greater in terms of quantity, frequency and potency of cannabis used compared to controls from the same population (Di Forti et al., 2015; Hasan et al., 2019; Marconi, Di Forti, Lewis, Murray, \& Vassos, 2016). There is converging evidence that cannabis is a component cause of psychotic disorder with well-replicated evidence of dose-response effects on psychotic outcomes (Marconi et al., 2016; Moore et al., 2007; Murray \& Di Forti, 2016; Ortiz-Medina et al., 2018; Schoeler et al., 2016).

When discussing psychosis and cannabis use, it is important to differentiate between psychotic-like experiences (PEs) and clinical psychotic disorder. Clinical psychotic disorder is relatively rare [incidence 21.4-26.6 per 100000 person years (Jongsma et al., 2018; Jongsma, Turner, Kirkbride, \& Jones, 2019)] whereas PEs are common and self-limiting [incidence 3000 per 100000 person-years (van Os, Linscott, Myin-Germeys, Delespaul, \& Krabbendam, 2009)] but can be a harbinger of more serious disorder (Werbeloff et al., 2012). However, the usual instruments for measuring PEs, such as the Peter's Delusions Inventory or the Community Assessment of Psychic Experience, either do not specifically index drug-induced experiences as part of the intoxication state (Stefanis et al., 2002) or specifically exclude them (Peters, Joseph, \& Garety, 1999; Peters, Joseph, Day, \& Garety, 2004).

Recreational drugs such as cannabis are used primarily for their immediate psychoactive effects. Factor analytic approaches have clustered cannabis intoxication experiences into psychoticlike experiences (cPLEs) and euphoric experiences (cEEs) (Barkus, Stirling, Hopkins, \& Lewis, 2006; Quinn, Wilson, Cockshaw, Barkus, \& Hides, 2017). cPLEs (sometimes called psychotomimetic experiences) are worthy of study in their own right as a model for psychotic disorder. cPLEs are increased in patients $v$. controls (Bianconi et al., 2016; D'Souza et al., 2005); increased in those with schizotypy and those at risk of schizophrenia (Barkus et al., 2006; Stirling et al., 2008; Vadhan, Corcoran, Bedi, Keilp, \& Haney, 2017). cPLEs may predict cessation of use in a non-clinical sample (Sami, Notley, Kouimtsidis, Lynskey, \& Bhattacharyya, 2018) whereas patients with psychotic disorders report using cannabis for affect regulation and socialisation, despite awareness that cannabis has a detrimental effect on positive symptoms of psychosis (Dekker, Linszen, \& De Haan, 2009).

One study to date has reported that patients experience both cPLEs and cEEs more frequently than controls but this did not take into account increased use in patients (Bianconi et al., 2016). Given that both increased rates of cannabis use and increased cannabis experiences are seen in FEP, it is not yet clear how these relate to each other and whether this differs from that of controls. No study to date has examined specifically the relationship between extent of use, cannabis experiences and psychotic disorder.

We therefore studied cannabis experiences in a large international sample of FEP patients and control lifetime cannabis users. To index these experiences we used the Cannabis Experiences Questionnaire an instrument specifically developed to assess retrospective cannabis experiences (Barkus et al., 2006; Stirling et al., 2008). We hypothesised that: (a) we would replicate the finding of increased cPLEs and cEEs in FEP patients $v$. controls; (b) extent of use (as indexed by frequency of use, money spent on cannabis and potency) would be associated with more frequent cannabis-induced experiences when adjusted for confounders and (c) this effect would differ between cases and controls: specifically that both cPLEs and cEEs would be more affected by heavy use in FEP patients $v$. controls. We included THC potency as a proxy of the dose of $\Delta^{9}$-tetrahydrocannabinol the primary psychomimetic constituent in cannabis (Morrison et al., 2009).

\section{Methods}

The European network of national networks studying gene environment interactions in schizophrenia (EU-GEI) study is a multicentre study comprising several workpackages (Van Os et al., 2014). Workpackage 2 comprises a 17 centre study across six countries (United Kingdom, Holland, Spain, France, Italy and Brazil) on FEP. Local Research Ethics Committee approval was obtained from each area.

\section{Sample selection}

Patients and controls were recruited between May 2010 and May 2015. Patients were identified by trained EUGEI researchers across the 17 sites and invited by clinical teams to participate. For patients inclusion criteria were: (i) age 18-64; (ii) presentation with FEP (ICD-10 F20-33) and (iii) residence within each defined locality. Exclusion criteria were: (i) organic psychosis (ICD-10: F09); (ii) psychosis due to acute intoxication (ICD-10: F1X.5) and (iii) previous contact with mental health services for psychosis. For full diagnostic data see online Supplementary Table S1.

Controls were recruited using a quota strategy derived from local demographic data to be representative for age, sex and ethnicity of the population at risk for each site. In order to sample controls in the first instance we undertook random sampling (a) from lists of all postal addresses and (b) from GP lists from randomly selected surgeries. The EUGEI study aimed to oversample certain groups (e.g. young men) using direct approaches such as local advertisements and leaflets at local shops and community centres. Controls were excluded if they had received a diagnosis or treatment for psychotic disorder.

Further details of the EUGEI study have previously been described (Jongsma et al., 2018). For the purpose of this study, analysing cannabis experiences, we only analysed data from participants (both patients and controls) who reported having ever used cannabis (lifetime use).

We did not use data from two centres: Maison-Blanche (France) as this centre did not collect controls and Verona (Italy) as cannabis use data were not complete. We excluded 12 cases (1.8\%) who were classified as having non-psychotic illness from the Diagnosis and Statistical Manual IV (DSM-IV) Operational Criteria Checklist (OPCRIT) screening of medical records.

\section{Measures}

\section{Demographics}

Data were collected on age, sex, ethnicity, site, country and years of education.

\section{Cannabis use}

A modified version of the Cannabis Experiences Questionnaire was used to collect cannabis use variables and cannabis 
experiences data (Barkus et al., 2006). This is a researcher administrated measure which collects self-reported data on: age of first use, frequency of use (categories: every day; more than once a week; a few times a month; a few times each year; only once or twice) and average money spent in a week (categories: less than $€ 2.50$; €2.50-€5.00; €5.00-€10.00, €11.00-€15.00; €16.00-€20.00 and 6 above $€ 20)$.

\section{Potency}

Since there is geographical variation in type of cannabis used we used an approach to determine users of low potency and high potency cannabis as has been reported before in the EUGEI study. Briefly participants were asked to name the strain they most often used in their own language. Strains were compared to mean reported THC concentration from published data from European Monitoring Centre for Drugs and Drug Addiction (European Monitoring Centre for Drugs \& Drug Addiction, 2016). High potency cannabis was categorised as THC $\geqslant 10 \%$ : including UK home-grown skunk/sensimilla UK Super Skunk, Italian home-grown skunk/sensimilla, Italian Super Skunk, the Dutch Nederwiet, Nederhasj and geimporteerde hasj, the Spanish and French Hashish (from Morocco); or 'low potency' with mean $\mathrm{THC}<10 \%$ including: hash/resin from UK and Italy, imported herbal cannabis from UK, Italy, Spain and France, Brazilian marijuana and hash and the Dutch Geimporteerde Wiet. For further details see Di Forti et al. (2019).

\section{Other drug use}

We collected data on the number of other drugs used, number of cigarettes smoked per day and units of alcohol consumed daily.

\section{Cannabis experiences}

Frequency of nine intoxication experiences - six cPLEs (feeling fearful; feeling crazy or mad; feeling nervy; feeling suspicious; hearing voices and seeing visions); and three cEEs (feeling happy; understanding the world better and being full of plans or ideas) were rated on a 5 point Likert scale: ( 0 rarely or never, 1 from time to time, 2 sometimes 3 more often than not, 4 almost always). These experiences were chosen as previous factor analytic approaches in the development of the Cannabis Experiences Questionnaire showed that these experiences load significantly onto respective subscales to index PEs and pleasurable effects (Barkus \& Lewis, 2008; Stirling et al., 2008).

\section{Statistical analysis}

Scores were obtained for cPLEs and cEEs by simple summation, as previously undertaken (Barkus et al., 2006; Sami et al., 2018). As there were half as many euphoric experiences items as PEs items, the scores for euphoric experiences were doubled rendering a scale of between 0 and 24 for both cPLEs and cEEs. Since such experiences can be conceptualised to index an underlying continuum both cPLEs and cEES were treated as continuous variables.

Extent of use was indexed primarily by the frequency of cannabis use and by potency. In further sensitivity analysis we replaced these with money spent on cannabis use. We calculated Pearson's Correlation coefficients to test whether the extent of use variables were correlated.

\section{Demographics and substance use}

We ascertained differences between demographic (age at assessment, sex, ethnicity, years in education and site) and cannabis use parameters (age of first use, frequency of use, money spent per week, potency, duration of use, lifetime and 12 month dependence) and other drug use parameters [cigarettes per day, units of alcohol in a day and other drugs ever used (excluding cannabis, alcohol, tobacco and caffeine)] using $t$ tests for continuous variables and $\chi^{2}$ for categorical variables.

\section{Main analysis}

We undertook to test the three hypotheses in a regression analyses framework. To test hypothesis (a) that caseness predicts experience: we regressed cannabis experiences (cPLEs and cEEs) as the dependent variables and caseness as the independent variables. To test hypothesis (b) that extent of use predicts experiences: we regressed cannabis experiences as the dependent variables and the extent of use variables as the independent variables. As the extent of use variables we entered frequency of cannabis use, and THC potency into separate models. These two variables (frequency of use and potency) were chosen to primarily index extent of use as they are both related to the extent of cannabis exposure but are distinct behaviours (for example one can use very frequently but at low potency). To test hypothesis (c): that there is an interaction between caseness and extent of use on cannabis experiences: we regressed cannabis experiences as the dependent variables and caseness and the extent of use variables alongside the interaction of caseness $\times$ extent of use. In all models we entered CPLEs as a regressor when the dependent variable was cEEs and cEEs as a regressor when the dependent variable was cPLEs to ensure that the predictors identified for relationships were independent of the other experience.

In sensitivity analyses for hypothesis (b) and (c) we ran the same regressions models using money spent on cannabis use rather than the frequency or potency variables.

We undertook a further sensitivity analysis to adjust for confounders. PEs may be explained by a number of putative other confounders other than caseness or extent of use. We hence adjusted for firstly demographic variables (age, sex and ethnicity) in secondary models and further to this substance misuse confounders in tertiary models (number of other drugs ever used, tobacco use and alcohol use) as other substance misuse may arguably be related to cannabis induced experiences to see if interaction effects survived putative confounders.

Finally we undertook a supplementary analysis to see if interactions for other classes of drugs were present on cPLEs. This analysis did not change the main findings reported in the manuscript and is reported in full in the Supplementary material.

cPLEs and cEEs demonstrated positive skew (cEEs 0.612, cPLEs 2.231). Because of violations of homoscedasticity in regression models we undertook all analyses using the robust regression option in STATA. For the purpose of estimation of $95 \%$ confidence intervals (see Fig. 1) we applied bootstrapping to inferential tests using 1000 samples and bias corrected and accelerated confidence intervals.

\section{Missing data}

Missing data rates are shown in online Supplementary Table S4. cPLEs were available for 598/655 (91.3\%) cases and 615/654 (94.0\%) controls whereas cEEs scores were available for $602 / 655$ $(91.9 \%)$ cases and $616 / 654(94.2 \%)$ controls. To ensure that results were not the result of systematic missing data, missing data was imputed using imputation analysis with chained equations (Azur, Stuart, Frangakis, \& Leaf, 2012) for cPLEs and 

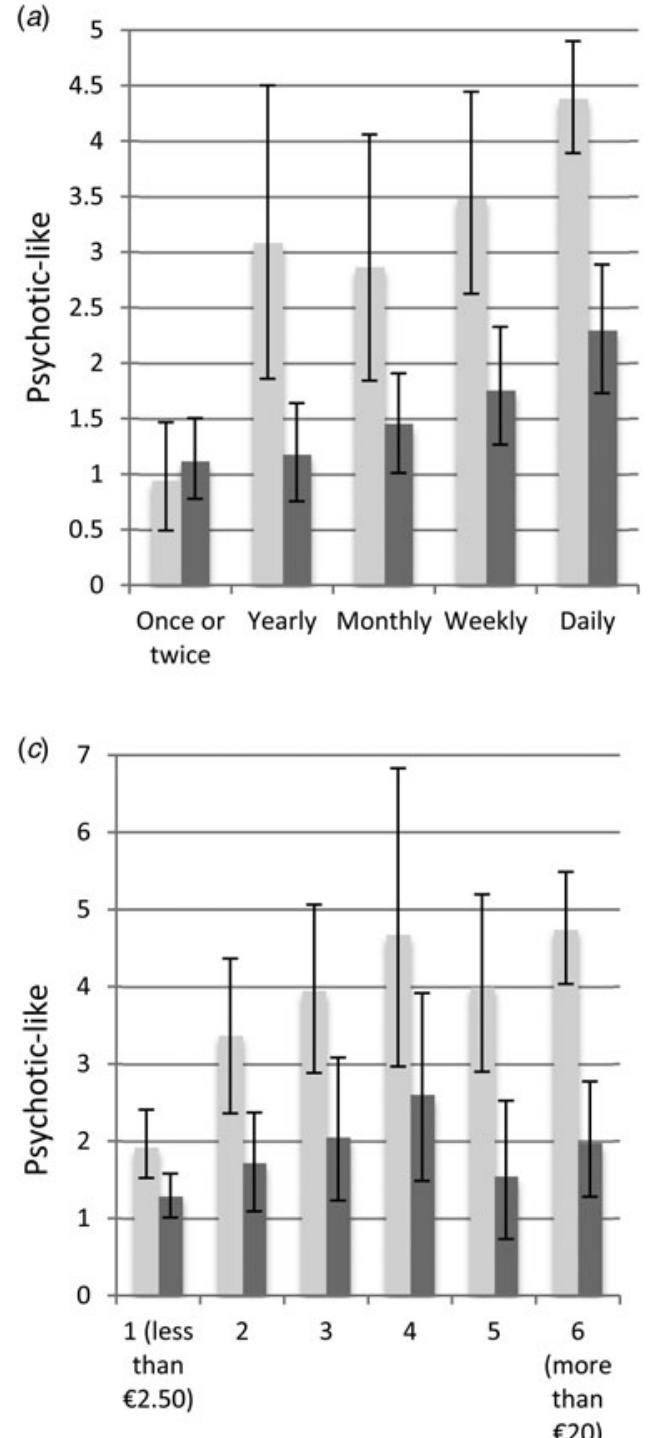

$(e)$

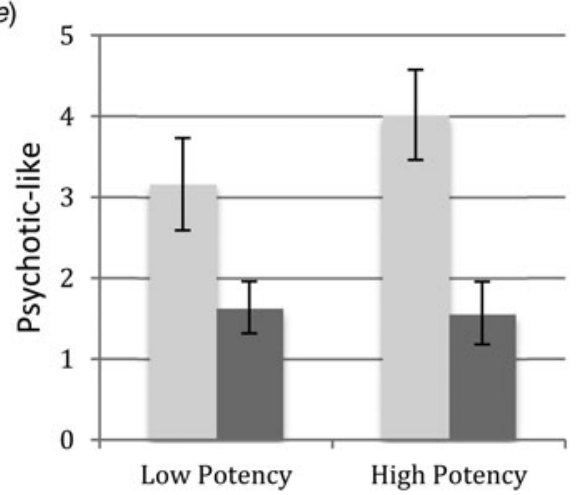

(b)

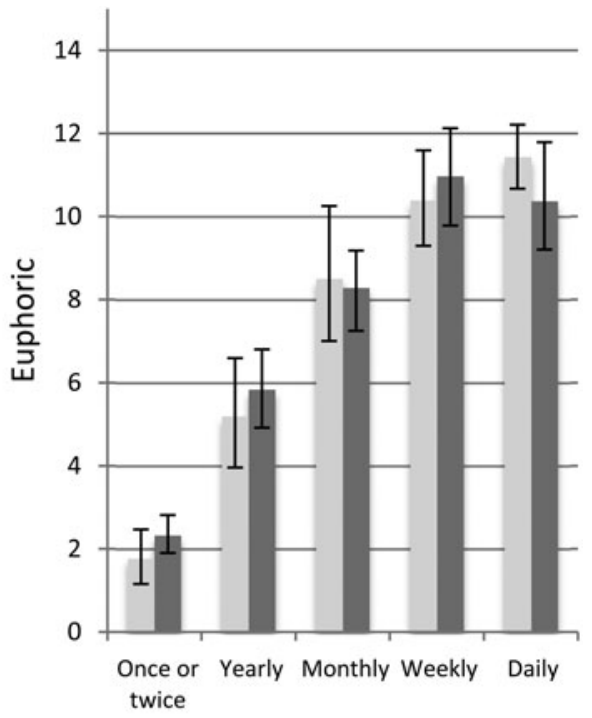

(d)

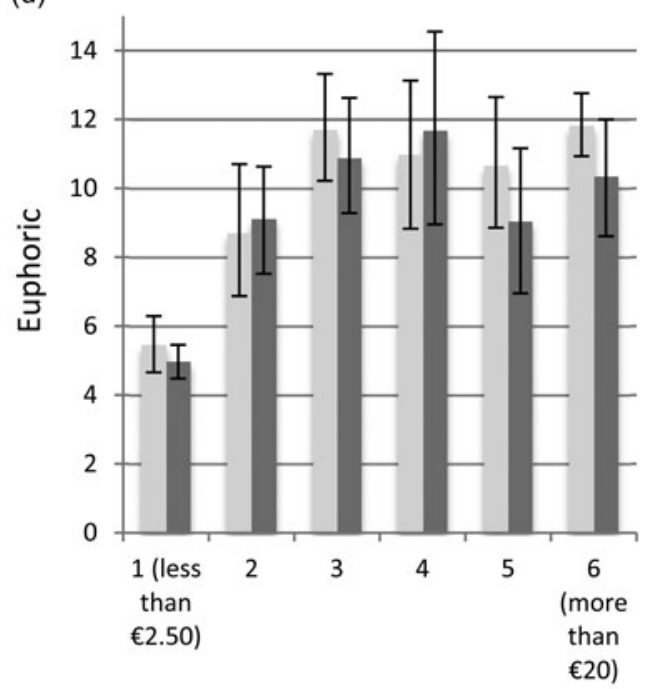

$(f)$

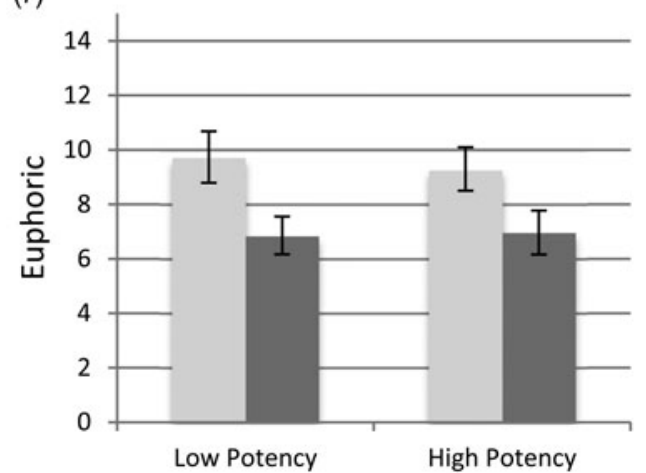

Fig. 1. Mean cannabis-induced psychotic-like experiences and euphoric experiences scores by case and control. $(a, b)$ Caseness $\times$ frequency of cannabis use interaction on cannabis-induced experiences. $(c, d)$ Caseness $\times$ money spent on cannabis per week interaction on cannabis-induced experiences. (e, $f$ ) Caseness $x$ potency of cannabis used interaction on cannabis-induced experiences. Legend: Light grey bars indicate FEP cases, dark grey bars for controls. Data drawn from complete case data. $Y$ axis represents mean psychotic like experiences and euphoric experiences scores $\pm 95 \%$ bootstrapped confidence interval.

cEEs as outcome variables, independent and auxillary variables. A total of 29 variables were included in the imputation model, including cannabis use variables (age of first use, social use, frequency, money spent and diagnosis of misuse), other drug use variables (tobacco use, alcohol use and number of other drugs used) and demographic variables (sex, age, ethnicity, site 
Table 1. Baseline characteristics between cases and controls

\begin{tabular}{|c|c|c|c|}
\hline & Case & Controls & $p$ value \\
\hline Male & $475(72.5 \%)$ & $355(54.3 \%)$ & $<0.001$ \\
\hline Missing & nil & nil & \\
\hline White & $415(63.6 \%)$ & $547(83.8 \%)$ & $<0.001$ \\
\hline Missing & nil & $1(0.2 \%)$ & \\
\hline Age at first contact $(\bar{x})$ & 28.07 & & \\
\hline Missing & nil & & \\
\hline Age at assessment $(\bar{x})$ & 28.51 & 34.30 & $<0.001$ \\
\hline Missing & nil & $1(0.2 \%)$ & \\
\hline Years in Education & 13.31 & 15.69 & $<0.001$ \\
\hline Missing $^{\star}$ & $12(1.8 \%)$ & $2(0.3 \%)$ & \\
\hline
\end{tabular}

and psychosis diagnosis). Fifty datasets were imputed with 10 cycles.

Regression and main analyses were run using the imputed dataset to account for missing data. Exploratory pairwise correlation between the extent of use variables was undertaken listwise since pairwise correlation is not available using the mi estimate command in STATA. Data was analysed using STATA version 15.

\section{Results}

Data were available for 1035 cases patients and 1382 controls. A total of 655 cases $(63.3 \%$ of all cases) and 654 controls $(47.3 \%$ of all controls) reported ever use of cannabis and data analysis was restricted to them.

\section{Baseline demographics}

Cases were significantly more likely than controls to be male, younger and have had fewer years of education (see Table 1). As expected, cases were more likely to have started using cannabis younger, more likely to have used more frequently, to have used more other drugs, and smoked more cigarettes per day (see Table 2). Detailed diagnostic, ethnicity and site data are presented in online Supplementary Tables S1-S3.

\section{Extent of use}

As expected the variables indexing extent of use were significantly correlated. Frequency of use weakly correlated with dichotomised potency $(r=0.121, p=0.001)$. Frequency of use strongly correlated with money spent on cannabis per week $(r=0.703, p<$ 0.001 ) whereas potency moderately correlated with money spent on cannabis $(r=0.211, p<0.001)$.

Caseness by frequency of use on CPLES and CEEs (hypothesis a) As hypothesised caseness predicted cPLEs independent of cEEs $(b=0.826, t=7.86, p<0.001)$ and predicted cEEs independent of cPLEs $(b=0.840, t=4.40, p<0.001)$ such that patients had both more frequent psychotic-like and euphoric experiences than controls.

Extent of use as a predictor of CPLES and CEES (hypothesis b) As hypothesised extent of use predicted cPLEs independent of cEEs whether the extent of use variable was frequency of use $(b=0.502, t=6.18, p<0.001)$, or potency $(b=0.543, t=2.36$, $p=0.019)$ such that increased extent of use predicted increased
Table 2. Comparison of cannabis use patterns between cases and controls

\begin{tabular}{|c|c|c|c|}
\hline & Case & Controls & $p$ value \\
\hline Age first tried cbs $(\bar{x})$ & 16.91 & 17.90 & $<0.001$ \\
\hline Missing ${ }^{\star}$ & $15(2.2 \%)$ & nil & \\
\hline \multicolumn{4}{|l|}{ Frequency of cbs use } \\
\hline Once or twice & $108(16.9 \%)$ & $240(36.8 \%)$ & \\
\hline Few times year & $65(10.2 \%)$ & $120(18.4 \%)$ & \\
\hline Few times month & $63(9.8 \%)$ & $100(15.3 \%)$ & \\
\hline >Once a week & $110(17.2 \%)$ & $100(15.3 \%)$ & $<0.001$ \\
\hline Every day & $294(45.9 \%)$ & $93(14.2 \%)$ & \\
\hline Missing ${ }^{\star}$ & $15(2.3 \%)$ & $1(0.2 \%)$ & \\
\hline \multicolumn{4}{|l|}{ Money spent per week on cbs } \\
\hline$<€ 2.50$ & $217(37.0 \%)$ & $415(68.4 \%)$ & \\
\hline$€ 2.50-€ 5.00$ & $52(8.8 \%)$ & $58(9.6 \%)$ & \\
\hline$€ 6-€ 10$ & $80(13.5 \%)$ & $42(6.9 \%)$ & \\
\hline$€ 11-€ 15$ & $36(6.1 \%)$ & $25(4.1 \%)$ & \\
\hline$€ 16-€ 20$ & $39(6.6 \%)$ & $24(4.0 \%)$ & \\
\hline$>€ 20$ & $170(28.6 \%)$ & $43(7.1 \%)$ & $<0.001$ \\
\hline Missing & $61(9.3 \%)$ & 47 (7.2\%) & \\
\hline Use of high potency cbs & $291(55.5 \%)$ & $223(43.1 \%)$ & $<0.001$ \\
\hline Missing & $131(20.0 \%)$ & $136(20.8 \%)$ & \\
\hline $\begin{array}{l}\text { Mean duration of cbs use } \\
\text { (years) }\end{array}$ & 9.41 & 9.82 & 0.418 \\
\hline Missing & $18(2.7 \%)$ & $28(4.3 \%)$ & \\
\hline Current cbs use & $223(34.2 \%)$ & $151(23.1 \%)$ & $<0.001$ \\
\hline Missing & $2(0.3 \%)$ & $1(0.2 \%)$ & \\
\hline $\begin{array}{l}\text { Lifetime DSM IV cbs } \\
\text { dependence }\end{array}$ & $247(39.3 \%)$ & $58(8.9 \%)$ & $<0.001$ \\
\hline Missing $^{\star}$ & $26(4.0 \%)$ & $3 / 654(0.5 \%)$ & \\
\hline $\begin{array}{l}\text { Last } 12 \text { month DSM IV cbs } \\
\text { dependence }\end{array}$ & $96(15.0 \%)$ & $12(1.8 \%)$ & $<0.001$ \\
\hline Missing $^{\star}$ & $26(5.2 \%)$ & $3(0.5 \%)$ & \\
\hline Number of other drugs tried & 1.47 & 0.97 & $<0.001$ \\
\hline Missing & nil & Nil & \\
\hline Cigarettes/roll-ups per day ${ }^{a}$ & 10.83 & 4.42 & $<0.001$ \\
\hline Missing ${ }^{\star}$ & $19(2.9 \%)$ & $8(1.2 \%)$ & \\
\hline Units of alcohol per day ${ }^{a}$ & 5.14 & 5.65 & 0.251 \\
\hline Missing & $143(21.8 \%)$ & $88(13.4 \%)$ & \\
\hline
\end{tabular}

cbs, cannabis

Mean numbers $(\bar{x})$ are given unless specified as a proportion. Significance testing undertaken via 2-tailed independent $t$ tests for continuous variables and $\chi^{2}$ tests for categorical variables. Missing data rates are italicised.

*Indicates significant difference $(p<0.05)$ in missing data between cases and controls ( $\chi^{2}$ test or Fisher's exact test where any single value $<=5$ ).

${ }^{a}$ Data was cleaned to remove outliers to max 40 cigarettes/day. Units of alcohol data cleaned to max of 30 units per day.

PEs. Similarly frequency of use predicted cEEs independent of cPLEs $(b=2.17, t=21.46, p<0.001)$ but this was not the case with potency $(b=0.210, t=0.55, p=0.58)$. 
Table 3. Primary models for cannabis-induced psychotic-like experiences caseness $\times$ extent of use interaction

\begin{tabular}{|c|c|c|c|}
\hline & $b$ & $t$ & $p$ \\
\hline \multicolumn{4}{|c|}{ (i) Model 1 - frequency of cannabis use as a predictor $F_{(4,1239.3)}=33.65, p<0.001$} \\
\hline Frequency of cannabis use ${ }^{a}$ & 0.794 & 4.74 & 0.001 \\
\hline Caseness $^{\mathrm{b}}$ & 1.354 & 6.20 & $<0.001$ \\
\hline Caseness $\times$ frequency of use ${ }^{c}$ & 0.229 & 3.49 & $<0.001$ \\
\hline $\begin{array}{l}\text { Cannabis-induced euphoric } \\
\text { experiences }\end{array}$ & 0.719 & 3.35 & $<0.001$ \\
\hline \multicolumn{4}{|c|}{ (ii) Model 2 - potency of cannabis as a predictor $F_{(41141.9)}=27.02, p<0.001$} \\
\hline Potency of cannabis ${ }^{a}$ & 1.241 & 2.28 & 0.023 \\
\hline Caseness & 0.142 & 0.42 & 0.676 \\
\hline Caseness $\times$ potency $^{c}$ & 0.438 & 2.04 & 0.042 \\
\hline $\begin{array}{l}\text { Cannabis-induced euphoric } \\
\text { experiences }\end{array}$ & 0.114 & 6.43 & 0.016 \\
\hline \multicolumn{4}{|c|}{ (iii) Model 3 - money spent on cannabis as a predictor $F_{(41235.8)}=33.35, p<0.001$} \\
\hline Money spent on cannabis ${ }^{a}$ & 0.591 & 4.56 & $<0.001$ \\
\hline Caseness & 0.267 & 1.59 & 0.112 \\
\hline $\begin{array}{l}\text { Caseness } \times \text { money spent on } \\
\text { cannabis }^{c}\end{array}$ & 0.177 & 3.29 & 0.001 \\
\hline $\begin{array}{l}\text { Cannabis-induced euphoric } \\
\text { experiences }\end{array}$ & 0.084 & 4.35 & $<0.001$ \\
\hline
\end{tabular}

Directions of effect as follows: ${ }^{\mathrm{a}}$ Increased extent predicts increased cPLEs; ${ }^{\mathrm{b}} \mathrm{FEP}$ predicts increased cPLEs; ${ }^{\mathrm{C}}$ Significant caseness $\times$ extent interaction.

\section{Sensitivity analysis (hypothesis b)}

For cPLEs results were the same when extent of use was indexed by money spent on cannabis per week $(b=0.397, t=6.17, p<$ 0.001 ) such that money spent predicted increased PEs. Similarly for $\mathrm{cEEs}$ increased money spent on cannabis predicted cEEs independent of cPLEs $(b=1.24, t=13.64, p<0.001)$.

\section{Interaction effects (hypothesis c)}

Model parameters for caseness by extent of use and their interaction on predicting cannabis PEs can be seen in Table 3 and caseness $\times$ extent of use scores for mean experiences are shown in Fig. 1.

\section{Caseness $\times$ frequency of use on CPLES}

There was a significant caseness effect $(b=1.354, t=6.20, p=$ 0.001 ); a significant effect for increased frequency of cannabis use $(b=0.794, t=4.74, p<0.001)$; and a significant interaction between group and frequency such that increasing frequency was associated with increased difference in cPLEs between cases and controls $(b=0.229, t=3.49, p=0.001)$.

\section{Caseness $\times$ potency on CPLES}

There was no significant effect of caseness $(p=0.676)$; but an effect for potency such that increased potency was associated with increased cPLEs $(b=1.241, t=2.28, p=0.023)$; and a significant interaction for caseness by potency $(b=0.438, t=2.04, p=$ 0.042).

\section{Caseness $\times$ extent of use variables on CEES}

There was evidence for increased euphoric experiences as cannabis use increased frequency $(b=2.152, t=9.44, p<0.001)$ but not for potency $(p=0.935)$. There was no significant interaction for either frequency or potency of cannabis use $\times$ caseness for cEEs as the dependent variable.

\section{Sensitivity analysis (hypothesis c)}

\section{Caseness $\times$ money spent on CPLES}

There was no significant effect of caseness $(p=0.112)$; but there was a significant effect for money spent such that cPLEs increased with more money spent $(b=0.591, t=4.56, p=0.001)$; and a significant interaction between caseness and money spent such that more money spent was associated with increased difference in cPLEs between cases and controls $(b=0.177, t=3.29, p=0.001)$.

\section{Caseness $\times$ extent of use variables on CEES}

There was evidence for increased euphoric experiences as cannabis use increased for money spent $(b=1.109, t=5.75, p<0.001)$. There was no significant interaction for any of the extent of use variables $\times$ caseness for $\mathrm{cEEs}$ as the dependent variable.

\section{Sensitivity analysis: adjustment for demographic and substance use covariates}

In secondary models we adjusted models for cPLEs as the dependent variables for demographic covariates: the interaction terms remained significant for caseness $\times$ frequency of use ( $b=0.207, t=3.19, p=0.001)$; caseness $\times$ money spent on cannabis $(b=0.163, t=3.07, p=0.002)$; caseness $\times$ potency $(b=0.446$, $t=2.08, p=0.038)$. In tertiary models we additionally adjusted for substance misuse covariates: the interaction terms remained significant for caseness $\times$ frequency of use $(b=0.208, t=3.23$, $p=0.001)$ and caseness $\times$ money spent on cannabis $(b=0.176$, $t=3.30, p=0.001)$; caseness $\times$ potency $(b=0.441, t=2.08, p=$ 0.038 ). We conclude that the caseness $\times$ extent of use interaction for increased cPLEs for patients $v$. controls is robust to a number of demographic and substance use confounders.

\section{Discussion}

To our knowledge, this represents the largest case-control study with extensive cannabis data in FEP ever undertaken. We (a) replicate the finding that cannabis intoxication experiences are more frequent in patients compared to controls; (b) show that extent of use as indexed by frequency of use and money spent on cannabis per week predict these experiences and (c) show that there is an interaction between caseness $\times$ frequency and caseness $\times$ money spent such that increasing levels of use are associated with more frequent PEs (but not euphoric experiences) in patients compared with controls. Importantly our findings are robust to a number of putative confounders including age, sex, gender and other substance use which would not explain any of these. Additionally we observe that these findings remains after accounting for various comorbid substance use parameters.

Importantly, these findings indicate that cannabis related experiences change as a function of extent of use. The Cannabis Experiences Questionnaire provides a measure of experiences as a proportion of total cannabis use, rather than a simple count of total experiences. A maximal score for cPLEs indicates that 
all six PEs were experienced every time cannabis was used whereas a minimal score indicates that these experiences were never or rarely experienced, irrespective of total number of times used. Hence higher scores indicate that the experience changes rather than simply indicating an increased total number of experiences due to increased number of times that cannabis is used.

Although not the main purpose of this analysis we also found of interest that a history of crack cocaine and inhalant abuse are associated with an increase in cannabis induced psychotic experiences whereas such experiences appear less frequent in the context of opiate abuse (see Supplementary material for full details). This may indicate that there is a cross sensation of drugs of abuse and is consistent with previous literature in which whereas cannabis and cocaine use are synergistic for psychosis experiences (Roncero et al., 2013a, 2013b) whereas opiate withdrawal is associated with psychosis experiences (Casado-Espada et al., 2019; Weibel, Mallaret, Bennouna-Greene, \& Bertschy, 2012), but this does not influence our main results.

This study extends previous work (Bianconi et al., 2016) by showing that extent of use is a key predictor of PEs and that FEP patients and controls have divergent experiences with increasing extent of use. Interestingly, the same relationship does not hold for euphoric experiences as cEEs scores, when stratified by extent of use, are well-matched between cases and controls. This suggests that specific mechanisms underlie the cannabis-related increases of PEs which may be related to genetic predisposition and may further support a GxE interaction as has been demonstrated on cannabis use with the risk of schizophrenia spectrum disorder (Guloksuz et al., 2019). One putative mechanism to be examined is that variation in the DRD2 and possibly AKT1 genes may render cases more likely to develop postsynaptic supersensitivity (Colizzi et al., 2015; Morgan, Freeman, Powell, \& Curran, 2016). Further work is needed to identify the specific genetic mechanisms which interact with increased extent of use.

Perhaps somewhat surprisingly we do not find the increased levels of use are associated with reduced euphoric experiences which would have been consistent with tolerance at heavier levels of use. Rather we find the relationship to indicate the opposite direction. There could be two possible explanations to this: either that repeated cannabis use is associated with increased sensitisation rather than tolerance to such experiences, or conversely that the association exists because individuals who have more euphoric experiences are more likely to use heavier amounts of cannabis. Further work is required to disentangle these two possibilities.

\section{Strengths and limitations}

The particular strengths of this study are (i) the sample size and (ii) the international sample. The limitations include: (i) the cross-sectional design, (ii) the use of self report measures and (iii) the lack of laboratory tests of potency.

The cross-sectional design precludes interpretation about temporal sequence of associations, which means it is difficult to disentangle whether extent of use causes enhanced experience or vice-versa. Euphoric experiences (cEEs) are likely to drive use whereas this is not the case for psychotic-like experiences (cPLEs) which have previously been shown to be associated with subsequent discontinuing use (Sami et al., 2018; Valmaggia et al., 2014). Furthermore in the case of cPLEs we included cEEs as a covariate in the model to regress out the association with euphoria. This may tentatively suggest a role for sensitisation to increasing levels of cannabis use for cPLEs in FEP.

Both exposure and outcome measures were based on selfreport. It is possible that because cannabis can be amnestic in nature exposure to cannabis may be misreported. However the relationships we report were similar for both frequency of cannabis use and money spent on cannabis per week (and it is arguable whether money spent is a more salient indicator of use than frequency of use) which increase our confidence in reporting these relationships. There are limited methods to determine extent of use over a longer period. Hair samples can provide an estimate of use over 3 months, but have been shown to be unreliable in a major observational study (Taylor, Sullivan, Ring, Macleod, \& Hickman, 2017). Moreover, self-report (but not hair) measures of cannabis use were found to predict acute psychotomimetic responses to cannabis (Curran et al., 2019). Additionally, selfreported data on cannabis potency is associated with its concentration of THC measured in the laboratory (Freeman et al., 2014) The outcome measures, although self-reported, were based on a considerable body of work validating cannabis experiences in non-clinical, although not in clinical populations (Barkus et al., 2006; Quinn et al., 2017). Another limitation is that the PEs were rated retrospectively rather than as state measures (e.g. in an experimental design administering THC).

On the other hand, a strength of utilising retrospective selfreport measures is that these are the experiences patients report to their clinicians during routine consultations. There were several differences between cases and controls, but the results persisted after adjusting for a wide variety of confounders. Perhaps most importantly cEEs were the same between patients and controls when accounted for extent of use: this indicates differences in cPLEs between FEP and controls to be specific to intrinsic biological differences between groups rather than to other confounders. One further limitation is that we did not account for non-psychosis comorbidities such as ADHD which may be synergistic with substance use for a psychotic outcome, as has been shown in the context of cocaine dependence (Carlos Roncero et al., 2013a). This could be undertaken in future studies.

\section{Clinical implications}

We consider this study to have a number of important findings in the clinical context. Although easily elicitable, clinicians do not routinely inquire about cPLEs in the clinical context. Our study suggests there are important differences between FEP patients and controls. Firstly our study adds to previous work (Bianconi et al., 2016), that patients experience cPLEs more frequently than controls. Secondly our work indicates that lower extent of use is associated with decreased cPLEs. This is in line with evidence suggesting that FEP who continue to use cannabis, especially daily high potency experience more relapses and worse clinical outcome than those who stop after illness onset (Schoeler et al., 2016). Thirdly we show that FEP patients are unlikely to derive greater euphoric effects compared to controls at increased levels of use, despite more frequent psychotic-like effects. In the absence of longitudinal data we are unable to definitively determine whether change in use effects experiences. However in the interim patients and particularly those with profound CPLEs should be advised that lower levels of use are associated with fewer PEs; and be advised that for high-potency cannabis there is limited evidence of the added euphoric effect. 
Taken together we have shown that extent of cannabis use is associated with enhanced psychotic-like but not euphoric experiences in FEP patients compared to controls. This may suggest a gene $\times$ evidence interaction for extent of use and genetic risk for psychosis on cannabis experiences. Further research should aim to determine the biological mechanism underpinning differences between patients and controls.

Supplementary material. The supplementary material for this article can be found at https://doi.org/10.1017/S0033291720000847.

Financial support. This work was supported by the European Community's Seventh Framework Programme under grant agreement No. HEALTH-F22010-241909 (Project EU-GEI). The Brazilian study was funded by the São Paulo Research Foundation under grant number 2012/0417-0. The funder was not involved in design and conduct of the study; collection, management, analysis and interpretation of the data; preparation, review or approval of the manuscript, and decision to submit the manuscript for publication. Dr Marta Di Forti is funded by the Medical Research Council. Dr Sami was supported by a Medical Research Council Clinical Research Training Fellowship (MR/ P001408/1). Dr Freeman was supported by a Senior Academic Fellowship from the Society for the Study of Addiction. Dr Marta Di Forti and Dr Musa Sami had full access to all the data in the study and take responsibility for the integrity of the data and the accuracy of the data analyses.

Conflict of interest. The authors have no conflicts of interest to declare in relation to the work presented in this paper.

\section{References}

Azur, M. J., Stuart, E. A., Frangakis, C., \& Leaf, P. J. (2012). Multiple imputation by chained equations - what is it, and how does it work. International Journal of Methods in Psychiatric Research, 20(1), 40-49. http://doi.org/10. 1002/mpr.329.Multiple

Barkus, E., \& Lewis, S. (2008). Schizotypy and psychosis-like experiences from recreational cannabis in a non-clinical sample. Psychological Medicine, 38 (9), 1267-1276. http://doi.org/10.1017/S0033291707002619

Barkus, E. J., Stirling, J., Hopkins, R. S., \& Lewis, S. (2006). Cannabis-induced psychosis-like experiences are associated with high schizotypy. Psychopathology, 39(4), 175-178. http://doi.org/PSP2006039004175[pii]\r10.1159/000092678

Bianconi, F., Bonomo, M., Marconi, A., Kolliakou, A., Stilo, S. A., Iyegbe, C., ... Di Forti, M. (2016). Differences in cannabis-related experiences between patients with a first episode of psychosis and controls. Psychological Medicine, 46(5), 995-1003. http://doi.org/10.1017/S0033291715002494.

Casado-Espada, N. M., Martín, C., De La Iglesia-Larrad, J. I., Alarcón, R. D. E., Fombellida, C. I., Fernández-Martín, L. C., \& Roncero, C. (2019). Psychotic symptoms following oxycodone withdrawal, case report and update. European Review for Medical and Pharmacological Sciences, 23(14), 63156320. http://doi.org/10.26355/eurrev_201907_18454

Colizzi, M., Iyegbe, C., Powell, J., Blasi, G., Bertolino, A., Murray, R. M., \& Di Forti, M. (2015). Interaction between DRD2 and AKT1 genetic variations on risk of psychosis in cannabis users: A case-control study. Npj Schizophrenia, 1(1), 15025. http://doi.org/10.1038/npjschz.2015.25

Curran, H. V., Hindocha, C., Morgan, C. J. A., Shaban, N., Das, R. K., \& Freeman, T. P. (2019). Which biological and self-report measures of cannabis use predict cannabis dependency and acute psychotic-like effects? Psychological Medicine, 49(9), 1574-1580. http://doi.org/10.1017/ S003329171800226X.

Dekker, N., Linszen, D. H., \& De Haan, L. (2009). Reasons for cannabis use and effects of cannabis use as reported by patients with psychotic disorders. Psychopathology, 42(6), 350-360. http://doi.org/10.1159/000236906.

Di Forti, M., Marconi, A., Carra, E., Fraietta, S., Trotta, A., Bonomo, M., ... Murray, R. M. (2015). Proportion of patients in south London with first-episode psychosis attributable to use of high potency cannabis: A case-control study. The Lancet Psychiatry, 2(3), 233-238. http://doi.org/10.1016/S2215-0366(14)00117-5

Di Forti, M., Quattrone, D., Freeman, T. P., Tripoli, G., Gayer-Anderson, C., Quigley, H., ... van der Ven, E. (2019). The contribution of cannabis use to variation in the incidence of psychotic disorder across Europe (EU-GEI): A multicentre case-control study. The Lancet Psychiatry, 6(5), 427-436. http://doi.org/10.1016/S2215-0366(19)30048-3

D’Souza, D. C., Abi-Saab, W. M., Madonick, S., Forselius-Bielen, K., Doersch, A., Braley, G., ... Krystal, J. H. (2005). Delta-9-tetrahydrocannabinol effects in schizophrenia: Implications for cognition, psychosis, and addiction. Biological Psychiatry, 57, 594-608. http://doi.org/10.1016/j.biopsych.2004. 12.006

European Monitoring Centre for Drugs and Drug Addiction. (2016). European drug report trends and developments 2016. Luxembourg: European Union Publications Office.

Freeman, T. P., Morgan, C. J. A., Hindocha, C., Schafer, G., Das, R. K., \& Curran, H. V. (2014). Just say "know": How do cannabinoid concentrations influence users' estimates of cannabis potency and the amount they roll in joints? Addiction (Abingdon, England), 109(10), 1686-1694. http://doi.org/ 10.1111/add.12634

Guloksuz, S., Pries, L. K., Delespaul, P., Kenis, G., Luykx, J. J., Lin, B. D., ... van Os, J. (2019). Examining the independent and joint effects of molecular genetic liability and environmental exposures in schizophrenia: Results from the EUGEI study. World Psychiatry, 18(2), 173-182. http://doi.org/10.1002/wps.20629

Hasan, A., von Keller, R., Friemel, C. M., Hall, W., Schneider, M., Koethe, D., ... Hoch, E. (2019). Cannabis use and psychosis: A review of reviews. European Archives of Psychiatry and Clinical Neuroscience. http://doi.org/ 10.1007/s00406-019-01068-z

Jongsma, H. E., Gayer-Anderson, C., Lasalvia, A., Quattrone, D., Mule, A., Szöke, A., ... Menezes, P. R. (2018). Treated Incidence of Psychotic Disorders in the Multinational EU-GEI Study, 75(1), 36-46. http://doi. org/10.1001/jamapsychiatry.2017.3554.

Jongsma, H. E., Turner, C., Kirkbride, J. B., \& Jones, P. B. (2019). International incidence of psychotic disorders, 2002-17: A systematic review and meta-analysis. The Lancet Public Health, 4(5), e229-e244. http://doi.org/ 10.1016/S2468-2667(19)30056-8

Marconi, A., Di Forti, M., Lewis, C. M., Murray, R. M., \& Vassos, E. (2016). Meta-analysis of the association between the level of cannabis use and risk of psychosis. Schizophrenia Bulletin, 42(5), 1262-1269. http://doi.org/ 10.1093/schbul/sbw003

Moore, T. H. M., Zammit, S., Lingford-Hughes, A., Barnes, T. R. E., Jones, P. B., Burke, M., \& Lewis, G. (2007). Cannabis use and risk of psychotic or affective mental health outcomes: A systematic review. Lancet, 370, 319328. http://doi.org/10.1016/S0140-6736(07)61162-3

Morgan, C. J. A., Freeman, T. P., Powell, J., \& Curran, H. V. (2016). AKT1 Genotype moderates the acute psychotomimetic effects of naturalistically smoked cannabis in young cannabis smokers. Translational Psychiatry, 6 (2), 1-6. http://doi.org/10.1038/tp.2015.219

Morrison, P. D., Zois, V., McKeown, D. A., Lee, T. D., Holt, D. W., Powell, J. F., ... Murray, R. M. (2009). The acute effects of synthetic intravenous Delta9-tetrahydrocannabinol on psychosis, mood and cognitive functioning. Psychological Medicine, 39(10), 1607-1616. http://doi.org/10.1017/ S0033291709005522

Murray, R. M., \& Di Forti, M. (2016). Cannabis and psychosis: What degree of proof do we require? Biological Psychiatry, 79(7), 514-515. http://doi.org/10. 1016/j.biopsych.2016.02.005

Myles, H., Myles, N., \& Large, M. (2015). Cannabis use in first episode psychosis: Meta-analysis of prevalence, and the time course of initiation and continued use. Australian and New Zealand Journal of Psychiatry, 50(3), 208-219. http://doi.org/10.1177/0004867415599846

Ortiz-Medina, M. B., Perea, M., Torales, J., Ventriglio, A., Vitrani, G., Aguilar, L., \& Roncero, C. (2018). Cannabis consumption and psychosis or schizophrenia development. International Journal of Social Psychiatry, 64(7), 690704. http://doi.org/10.1177/0020764018801690.

Peters, E., Joseph, S., Day, S., Garety, P. (2004). Measuring delusional ideation: The 21-item Peters et Al. Delusions Inventory (PDI). Schizophrenia Bulletin, 30(4), 1005-1022. http://doi.org/10.1093/oxfordjournals.schbul. a 007116

Peters, E. R., Joseph, S. A., Garety, P. A. (1999). Measurement of delusional ideation in the normal population: Introducing the PDI (Peters et al. Delusions Inventory). Schizophrenia Bulletin, 25(3), 553-576. http://doi. org/10.1093/oxfordjournals.schbul.a033401 
Quinn, C. A., Wilson, H., Cockshaw, W., Barkus, E., \& Hides, L. (2017). Development and validation of the cannabis experiences questionnaire intoxication effects checklist (CEQ-I) short form. Schizophrenia Research, 189, 91-96. http://doi.org/10.1016/j.schres.2017.01.048.

Roncero, C., Daigre, C., Gonzalvo, B., Valero, S., Castells, X., Grau-López, L., ... Casas, M. (2013a). Risk factors for cocaine-induced psychosis in cocaine-dependent patients. European Psychiatry, 28(3), 141-146. http:// doi.org/10.1016/j.eurpsy.2011.06.012

Roncero, C., Daigre, C., Grau-López, L., Rodríguez-Cintas, L., Barral, C., Pérez-Pazos, J., ... Casas, M. (2013b). Cocaine-induced psychosis and impulsivity in cocaine-dependent patients. Journal of Addictive Diseases, 32(3), 263-273. http://doi.org/10.1080/10550887.2013.824330

Sami, M., Notley, C., Kouimtsidis, C., Lynskey, M., \& Bhattacharyya, S. (2018). Psychotic-like experiences with cannabis use predict cannabis cessation and desire to quit: A cannabis discontinuation hypothesis. Psychological Medicine, 49(1), 1-10. http://doi.org/10.1017/S0033291718000569.

Schoeler, T., Petros, N., Di Forti, M., Klamerus, E., Foglia, E., Ajnakina, O., ... Bhattacharyya, S. (2016). Effects of continuation, frequency and type of cannabis use on relapse in the first two years following onset of psychosis - an observational study. The Lancet. Psychiatry, 366(16), 1-7. http://doi.org/10. 1016/S2215-0366(16)30188-2

Stefanis, N. C., Hanssen, M., Smirnis, N. K., Avramopoulos, D. A., Evdokimidis, I. K., Stefanis, C. N., ... Van Os, J. (2002). Evidence that three dimensions of psychosis have a distribution in the general population. Psychological Medicine, 32(2), 347-358. http://doi.org/10.1017/S0033291701005141

Stirling, J., Barkus, E. J., Nabosi, L., Irshad, S., Roemer, G., Schreudergoidheijt, B., \& Lewis, S. (2008). Cannabis-induced psychotic-like experiences are predicted by high schizotypy: Confirmation of preliminary results in a large cohort. Psychopathology, 41(6), 371-378. http://doi.org/10.1159/000155215
Taylor, M., Sullivan, J., Ring, S. M., Macleod, J., \& Hickman, M. (2017). Assessment of rates of recanting and hair testing as a biological measure of drug use in a general population sample of young people. Addiction, 112(3), 477-485. http://doi.org/10.1111/add.13645

Vadhan, N. P., Corcoran, C. M., Bedi, G., Keilp, J. G., \& Haney, M. (2017). Acute effects of smoked marijuana in marijuana smokers at clinical highrisk for psychosis: A preliminary study. Psychiatry Research, 257, 372374. http://doi.org/10.1016/j.psychres.2017.07.070

Valmaggia, L. R., Day, F. L., Jones, C., Bissoli, S., Pugh, C., Hall, D., ... McGuire, P. K. (2014). Cannabis use and transition to psychosis in people at ultra-high risk. Psychological Medicine, 44(12), 2503-2512. http://doi.org/ 10.1017/S0033291714000117

van Os, J., Linscott, R. J., Myin-Germeys, I., Delespaul, P., \& Krabbendam, L. (2009). A systematic review and meta-analysis of the psychosis continuum: Evidence for a psychosis proneness-persistence-impairment model of psychotic disorder. Psychological Medicine, 39(2), 179-195. http://doi.org/ 10.1017/S0033291708003814

Van Os, J., Rutten, B. P., Myin-Germeys, I., Delespaul, P., Viechtbauer, W., Van Zelst, C., ... Mirjanic, T. (2014). Identifying gene-environment interactions in schizophrenia: Contemporary challenges for integrated, large-scale investigations. Schizophrenia Bulletin, 40(4), 729-736. http://doi.org/10 1093/schbul/sbu069

Weibel, S., Mallaret, M., Bennouna-Greene, M., \& Bertschy, G. (2012). Case report: A case of acute psychosis after buprenorphine withdrawal. The Journal of Clinical Psychiatry, 73(6), e756. http://doi.org/10.4088/jcp.11cr07608

Werbeloff, N., Drukker, M., Dohrenwend, B. P., Levav, I., Yoffe, R., Van Os, J., .. Weiser, M. (2012). Self-reported attenuated psychotic symptoms as forerunners of severe mental disorders later in life. Archives of General Psychiatry, 69(5), 467-475. http://doi.org/10.1001/archgenpsychiatry.2011.1580 